\title{
POBREZA MULTIDIMENSIONAL EM SILVEIRA MARTINS/RS: UMA APLICAÇÃO DO MÉTODO ALKIRE-FOSTER (AF)
}

Data de submissão:03/08/2017 Aceite: 13/04/2018

Solange Regina Marin ${ }^{1}$ Sirlei Glasenapp ${ }^{2}$

Carine de Almeida Vieira ${ }^{3}$

Géssica Mathias Diniz ${ }^{4}$

Melody de Campos Soares Porsse ${ }^{5}$ Janaína Ottoneli ${ }^{6}$

\section{RESUMO}

A Abordagem das Capacitações, conforme a proposta de Amartya Sen (1979, 1985, 1987, 1999a, 1999b), analisa a pobreza para além da renda monetária ao considerar dimensões como condições de saúde, educação, saneamento, entre outras que são valoradas pelas pessoas. A partir dessa proposta, Alkire e Foster (2007) desenvolveram um método de mensuração da pobreza que agrega os diversos aspectos da vida das pessoas em uma medida multidimensional. O objetivo deste trabalho é explorar o método Alkire-Foster (AF) e apresentar a medida geral obtida em um estudo no município de Silveira Martins (RS). A medida final revelou que as pessoas possuem maiores privações nas dimensões 'liberdade desfrutada na comunidade', no 'acesso à renda', 'trabalho', 'serviços básicos' e 'educação', o que corrobora a perspectiva seniana de que a pobreza vai além da renda monetária. Com base no Método AF, possibilita-se que sejam elaboradas políticas voltadas às dimensões em que a maioria das pessoas sofre maior privação.

PALAVRAS-CHAVE: Método Alkire-Foster. Abordagem das Capacitações. Pobreza Multidimensional. Silveira Martins (RS).

\footnotetext{
1 Possui graduação em Ciências Econômicas pela Universidade Estadual de Maringá, UEM, mestrado em Desenvolvimento Rural pela Universidade Federal do Rio Grande do Sul, UFRGS e doutorado em Desenvolvimento Econômico pela Universidade Federal do Paraná, UFPR. Florianópolis - SC - Brasil. E-mail: solmarin@gmail.com

2 Possui graduação em administração pela Universidade Federal de Santa Maria, UFSM, mestrado em Engenharia de Produção pela Universidade Federal de Santa Maria, UFSM e doutorado em Desenvolvimento Rural pela Universidade Federal do Rio Grande do Sul, UFRGS. Santa Maria - RS - Brasil. E-mail: sglasenapp11@gmail.com

3 Possui graduação em Ciências Econômicas pela Universidade Federal de Santa Maria, UFSM, mestrado em Economia e Desenvolvimento pela UFSM e doutorado em andamento em Ciências Humanas e Sociais, Economia, Desenvolvimento e Sociedade pela Universidade Federal do ABC. Santa Maria - RS - Brasil. E-mail: carine.a.vieira@gmail.com

4 Possui graduação em Ciências Econômicas pela Universidade Federal de Santa Maria, UFSM, mestrado em Economia e Desenvolvimento pela UFSM e doutorado em andamento em Desenvolvimento Econômico pela Universidade Federal do Paraná, UFPR. Curitiba - PR - Brasil. E-mail: gessica92eco@gmail.com

5 Possui graduação em Ciências Econômicas pela Universidade Estadual de Maringá, UEM, mestrado em Economia pela Universidade Federal da Paraíba, UFPB, doutorado em Administração pela Universidade Federal do Rio Grande do Sul, UFRGS. Curitiba - PR - Brasil. E-mail: msporsse@gmail.com

6 Possui graduação em Administração pela Universidade Federal de Santa Maria, UFSM, mestrado em Economia pela Universidade Federal do Rio Grande do Norte, UFRN, doutorado em andamento em Administração pela Universidade Federal de Santa Maria, UFSM. Santa Maria - RS - Brasil. E-mail: janainaottoneli@gmail.com
} 


\section{INTRODUÇÃO}

O conceito de pobreza tem evoluído e com ele as propostas de medida da pobreza. A renda monetária, até a década de 1970, era a única dimensão utilizada para medir a pobreza, com uma única linha de corte que distinguia pobres de não pobres. A partir da proposta multidimensional desenvolvida por Sen (1979), com a Abordagem das Capacitações, a pobreza passou a ser definida como a privação de uma pessoa com relação ao acesso aos funcionamentos valorados por ela, à limitação do seu conjunto capacitário (grupo de funcionamentos que pode escolher realizar - liberdade de escolha). O conjunto de dimensões consideradas na mensuração da pobreza foi ampliado, englobando, além da renda, a saúde, a educação, as condições de saneamento e outros funcionamentos valorados pelas pessoas.

Baseado na Abordagem das Capacitações, a partir da década de 1990, o desenvolvimento humano passou a ser conceituado como o processo de expansão das possibilidades de escolha das pessoas, e a pobreza passou a ser definida como a negação dessa oportunidade. Com a evolução do conceito de pobreza, os métodos de mensuração da pobreza também se modificaram. Houve um esforço para a criação de metodologias que propiciassem agregação de um maior número de variáveis sobre os diversos aspectos da vida das pessoas, via medidas multidimensionais.

O Índice de Pobreza Multidimensional (IPM) é uma medida de pobreza resultante do Método Alkire-Foster (AF), que está fundamentado na abordagem proposta por Sen $(1979,1985$, 1987), e propõe uma forma de mensurar quão multidimensionamente pobres são aqueles identificados como privados. Esse método, elaborado por Alkire e Foster (2007), resulta em uma medida que apresenta algumas vantagens na sua utilização, como as possibilidades de escolha de indicadores e dimensões (cada dimensão é composta por um conjunto de indicadores) flexível de acordo com a localidade e de atribuição de pesos iguais ou não a esses indicadores/dimensões, dependendo do objetivo. Além disso, permite o uso de uma variedade de dados (cardinais, ordinais ou categorias), podendo também utilizar uma combinação dessas informações. A medida reflete a amplitude da pobreza por meio de múltiplas privações que uma família sofre através de um único número, que pode ser decomposto em outros, e esses outros valores podem ser comparados entre regiões, entre grupos específicos e até mesmo entre dimensões ou indicadores. Tendo em vista esse desenvolvimento da análise da pobreza, o presente trabalho tem como objetivo aplicar o Método Alkire-Foster (AF) na construção de uma medida geral e desagregada da pobreza multidimensional em bairros no município de Silveira Martins (RS), com informações obtidas via pesquisa de campo.

O artigo está estruturado em quatro seções além desta introdução. Na primeira, são apresentados o embasamento teórico e o Método AF; na conseguinte, é exposto o método aplicado ao município de Silveira Martins. Na terceira seção, são discutidos os resultados da aplicação do Método AF. Por fim, são apresentadas algumas considerações.

\section{EMBASAMENTO TEÓRICO E O MÉTODO ALKIRE-FOSTER}

Nesta seção é apresentada a fundamentação teórica do Método AF, que propõe uma medida de pobreza multidimensional baseada na Abordagem das Capacitações de Amartya Sen $(1979,1985,1987)$. 


\subsection{ABORDAGEM DAS CAPACITAÇÕES E POBREZA}

A proposta da Abordagem das Capacitações é expandir a análise da pobreza para além da renda monetária, englobando diversos funcionamentos (estar bem nutrido, ser alfabetizado, entre outros) e a liberdade relacionada à possibilidade de escolha (capacitações ${ }^{7}$ ) por parte das pessoas de realizarem, dentre os funcionamentos, aqueles considerados de maior importância para as suas vidas.

O bem-estar passa a ser entendido não apenas como aumento de renda per capita, mas também como uma expansão do que as pessoas podem ser e fazer. Através desse viés da noção de bem-estar, diferentemente da interpretação da Economia de Bem-Estar tradicional, exige-se a ampliação do foco informacional para além da utilidade e a inclusão de informações desde as mais básicas, como saúde, educação e condições de moradia, até as mais complexas, como autonomia dos indivíduos ou ser feliz.

O desenvolvimento humano passa a ser caracterizado como um processo de expansão das capacitações humanas (das liberdades substantivas) (SEN, 1999a). Os funcionamentos, na concepção de Sen (1992, 1999a), são os elementos que as pessoas podem considerar valiosos, e eles podem variar desde estar bem alimentado até realizações mais complexas, como ser feliz. O conjunto de elementos ou funcionamentos que as pessoas conseguem realizar constitui a sua capacitação. Os funcionamentos refletem o que uma pessoa está fazendo, enquanto a capacitação representa o que a pessoa pode fazer ou realizar. Robeyns (2000) destaca que as definições de funcionamentos e de capacitações são próximas, porém distintas. A primeira refere-se a algo que foi ou que pode ser alcançado, e a segunda reflete a possibilidade de alcançar o que se deseja. Os funcionamentos são, por exemplo, as condições de vida em seus diferentes aspectos, enquanto a capacitação se refere às liberdades, ou seja, às oportunidades reais que as pessoas têm em suas vidas.

A abordagem seniana tem, portanto, duas partes constituintes - funcionamentos e capacitações. Sem uma ou outra, a formulação da proposta normativa de Sen (1999a) ficaria incompleta. O conceito de funcionamento tem raiz aristotélica e reflete as coisas que a pessoa valora fazer e ser (doing and being) (SEN, 1999a, p. 74-76). Ao tratar da distinção entre meios e fins humanos, Sen (1999a) cita Aristóteles, para quem a riqueza não é o bem em si que procuramos; ela é alguma coisa útil que procuramos por causa de algo mais. "Aristotle saw 'the good of human being' in terms of the richness of 'life in the sense of activity', and thus argued for taking human functionings as objects of value" (SEN, 1999a, p. 12). Nesse sentido, a renda seria um meio para o alcance de outras realizações.

A Abordagem das Capacitações defende o estudo da pobreza por fontes não monetárias através de uma visão multidimensional, que contemple os vários aspectos da vida das pessoas, além da questão monetária. A erradicação da pobreza exige que sejam retiradas as fontes de privação das liberdades humanas, ou seja, deve-se levar em consideração não somente a renda monetária, mas também a vida que o indivíduo deseja. Ele deve ser livre de privações para obter o que almeja, ou seja, ter um conjunto capacitário que proporcione os funcionamentos desejados.

Diante da complexificação do conceito de pobreza, surgiram propostas de mensuração da pobreza ${ }^{8}$ com metodologias multidimensionais. Alkire e Santos (2010) ressaltam que o inte-

7 Capacitação se refere à liberdade que a pessoa tem de alcançar os funcionamentos valorados.

8 Sen (1976) argumenta que uma medida de pobreza deve cumprir os axiomas da transferência e da monotonicidade. O primeiro axioma defende que o índice deve ser sensível e ter um incremento na mensuração da pobreza quando uma pessoa abaixo da linha de pobreza transfere parte de sua renda para alguém mais rico. $\mathrm{O}$ axioma da monotonicidade refere-se à sensibilidade em relação à distribuição de renda entre os pobres, ou seja, uma redução na renda de uma pessoa abaixo da linha de pobreza deve ter impacto no índice, de maneira em que haja um incremento neste. Se for medida multidimensionalmente, a pobreza do indivíduo não será restrita à renda, e sim à quantidade de dimensões ou indicadores de que o indivíduo está privado. Nesse sentido, o aumento no número de privações refletirá na medida final. 
resse por medidas multidimensionais é guiado por três razões. A primeira é que medidas como as linhas de pobreza são consideradas cada vez mais insuficientes, e muitos países têm interesse em construir índices que captem múltiplas privações para obter resultados mais próximos à realidade sobre o bem-estar de sua população, ao longo dos anos. A segunda razão apresentada pelos autores é a identificação de beneficiários para programas públicos; em muitos países há serviços públicos que são direcionados aos pobres, e métodos de medição através da renda frequentemente são errôneos. A última razão menciona a avaliação de processos em que medidas multidimensionais são construídas para monitoramento e avaliação e podem contribuir para a ponderação dos impactos de políticas e programas públicos.

O Relatório de Desenvolvimento Humano (PNUD, 2010) apresenta o Índice de Pobreza Multidimensional (IPM) ${ }^{9}$, que emprega o Método AF alicerçado na Abordagem das Capacitações. A medida, desenvolvida por Alkire e Foster (2007), reflete a amplitude e a complexidade da pobreza por meio da inclusão de múltiplas privações que uma família sofre por meio de um único número, que, como foi dito, pode ser decomposto em outros, e estes outros valores podem ser comparados entre regiões, grupos específicos e dimensões/indicadores. A próxima seção apresenta mais detalhadamente as especificidades do Método AF.

\subsection{O MÉTODO ALKIRE-FOSTER (AF)}

A mensuração proposta por Alkire e Foster (2007) pode ser dividida em dois grandes passos: o da identificação - em que os indivíduos são identificados como pobres ou não - e o de agregação - que consiste na reunião dos dados dos indivíduos pobres em um indicador de pobreza. Uma das vantagens do Método AF é o método de identificação - dual cut-off - em que é feito uso de dois cortes ou duas linhas para a identificação dos indivíduos que são multidimensionalmente pobres. O primeiro corte é interno a cada indicador (o indivíduo será considerado privado ou não nesse indicador), e o segundo engloba dois ou mais indicadores (representa um número mínimo de indicadores em que cada indivíduo deve ser privado para ser considerado pobre em nível multidimensional).

Os métodos mais utilizados para o segundo corte, destacam Alkire e Foster (2007), são o da união e o da intersecção. O primeiro define que, para o indivíduo ser considerado pobre de forma multidimensional, basta ser privado em um indicador, contudo, quando for utilizado um conjunto de vários indicadores, quase toda a amostra será considerada multidimensionalmente pobre. Já o método da intersecção estabelece que serão considerados pobres em nível multidimensional aqueles que forem privados em todos indicadores, porém os autores argumentam que não ser privado em uma dimensão não é o suficiente para evitar a pobreza. Sendo assim, Alkire e Foster (2007) sugerem o uso de um número intermediário para o segundo corte, ou seja, um valor que fique entre o método da interseç̧ão e o da união. A agregação dos dados referentes aos pobres em uma medida final $\left(\mathrm{M}_{0}\right)$ é realizada com base na medida FosterGreer-Thobercke (FGT) ${ }^{10}$.

O Método AF é composto por doze passos, que, ao fim, resultam no IPM. Os passos são os seguintes:

(1) escolher a unidade de análise: a unidade de análise pode ser um indivíduo ou família, ou ainda uma comunidade, escola, clínica ou outra unidade;

\footnotetext{
9 Ressalta-se que, no Relatório do Desenvolvimento Humano de 1990, o PNUD já havia formulado o IDH (como medida de desenvolvimento) e, em 1997, o IPH (como medida de pobreza). Em 2015, o IPH foi substituído pelo MPI. Já que essas duas medidas possuem focos diferentes (o IPH mensura o desenvolvimento, e o MPI, a pobreza), elas não são comparáveis. Para maiores detalhes sobre o assunto, ver Anand e Sen (1997).

10 A medida FGT é apresentada em publicação do Banco Mundial (2005).
} 
(2) escolher as dimensões: a escolha das dimensões é importante e menos aleatória do que as pessoas assumem;

(3) definir os indicadores: para cada uma das dimensões selecionadas, é necessário definir os indicadores;

(4) estabelecer linhas de pobreza: um corte de pobreza é definido para cada um dos indicadores, de forma que identifiquem o indivíduo como privado ou não privado em determinada dimensão/indicador. Por exemplo, se o indicador é anos de estudo (Quantos anos de estudos você completou?), caso a pessoa seja analfabeta ou tenha estudado até a quarta série, será considerada privada (P), porém, se frequentou a quinta série ou mais, é não privada (NP);

(5) aplicar a primeira linha de pobreza: comparar a resposta da pessoa com cada corte considerado. Por exemplo, na dimensão saúde, quando o indicador for IMC e a resposta for um valor que não está contido no intervalo aceitável pela OMS, a pessoa será considerada privada nesse indicador, e sua condição será codificada pela letra P; caso contrário, seria não privada (NP);

(6) contar o número de privações de cada indivíduo: verificar a quantidade de indicadores nos quais a pessoa é privada;

(7) estabelecer o segundo corte de pobreza ( $k$ ): indica o número de dimensões/indicadores em que uma pessoa deve ser privada para ser considerada multidimensionalmente pobre;

(8) aplicar a linha $k$ : com base no corte $k$, obter o grupo de pessoas pobres, e omitir os dados das pessoas que não são consideradas pobres (os não pobres recebem zero nos resultados das dimensões/indicadores);

(9) calcular a incidência H: a proporção de pessoas pobres que são privadas em $k$ ou mais dimensões $(d)$ - indicadores, neste caso - sobre o total de indivíduos analisados;

(10) calcular o hiato de pobreza média A: A corresponde ao número médio de privações que a pessoa pobre sofre. É calculada somando a proporção de privações totais que cada pessoa sofre (por exemplo, a pessoa 1 sofre privação em 4 das seis dimensões/indicadores e a pessoa 4 sofre privação em 6 de 6$)$ e dividindo o resultado pelo número total de pessoas pobres. $A=(4 / 6$ $+6 / 6) / 2$ = 5/6;

(11) calcular a incidência ajustada $\mathrm{M}_{0}: \mathrm{M}_{0}=\mathrm{H} \times \mathrm{A}$;

(12) decompor e segmentar: decompor por grupos e segmentar por dimensões.

A utilização de dados primários, obtidos via pesquisa de campo, permite que as dimensões sejam definidas de acordo com a percepção que os próprios indivíduos têm sobre o contexto em que estão inseridos. A determinação das dimensões a serem ponderadas na mensuração da pobreza com base em um mecanismo participativo possibilita ao pesquisador obter resultados condizentes com a diversidade de realidades e necessidades de cada unidade de análise. "Although the AF methodology has a specific structure for identification and aggregation, its implementation is flexible: parameters such as dimensions, cutoffs, and weights can be chosen to reflect the purpose of the measure and its context" (ALKIRE; FOSTER, 2011, p. 14).

Nesse sentido, a Abordagem das Capacitações dá respaldo à construção da medida proposta por Alkire e Foster (2007), pois a seleção dos funcionamentos (dimensões) para Amartya Sen, conforme Alkire (2002), deve ser realizada com base em julgamentos de valor (distintos de acordo com o grupo focalizado), que, em muitos casos, pode ser via debate público.

Para Alkire (2005), a operacionalização da Abordagem das Capacitações deve considerar algumas observações: a primeira é que uma lista de capacitações básicas não será relevante para todos os processos de avaliação e mensuração; a seleção dos funcionamentos ou capacitações deve ser feita continuamente. A segunda é que a operacionalização deve ocorrer em 
diferentes países, em diferentes níveis e envolver diversos problemas. A terceira observação refere-se ao "manejo" da Abordagem das Capacitações. Segundo Alkire (2005), ela possui muitos graus de liberdade, mas, em situações concretas, deve ser mais restrita. A última observação é que a abordagem não é operacionalizada por qualquer pesquisador; é necessária a sensibilidade por parte dele com relação ao contexto a ser analisado, dado que Sen (1979) não impõe uma lista de capacitações básicas a ser utilizada. O pesquisador é livre para defini-las de acordo com o problema com que se depara.

A abordagem conduz a um mecanismo de seleção participativo e não se cristaliza dentro de uma teoria (ALKIRE, 2005). A operacionalização da Abordagem das Capacitações não é uma tarefa fácil, segundo Alkire (2005, p. 130), ela deve funcionar como em uma empresa colaborativa, com vários pesquisadores trabalhando sobre diferentes aspectos ao mesmo tempo e mantendo a comunicação para construírem um grupo de simplificações e criarem uma dinâmica.

O método proposto por Alkire e Foster (2007) através da combinação, na medida final, do hiato de pobreza média $(A)$ e da incidência de pobreza $(H)$ não viola o axioma da monotonicidade. Em outras palavras, se um indivíduo for privado em três dimensões e, depois de algum evento, se tornar privado em quatro dimensões, ou seja, se houver um aumento no número de privações do indivíduo, pelo axioma da monotonicidade, a medida final aumentará. Outro axioma importante é o da transferência, o que significa que a transferência da renda de uma pessoa abaixo da linha de pobreza para alguém com maiores rendimentos ocasionaria um aumento na incidência de pobreza (SEN, 1976).

O Método AF também satisfaz o axioma da decomponibilidade, permitindo que o índice final seja desagregado em subgrupos (regiões, etnias, gênero etc.) e tornando possível a identificação das características da pobreza multidimensional de cada um desses grupos. $O$ índice também possibilita a desagregação por dimensão, o que revela quais dimensões têm maior contribuição na pobreza total de qualquer grupo (ALKIRE et al, 2015).

Por fim, Alkire e Santos (2013) salientam que outra vantagem das medidas AF é sua flexibilidade em relação ao uso de diferentes tipos de dados, como variáveis cardinais, ordinais e em categorias. Como há a codificação, através do dual cut-off, das variáveis em privado e não privado, não há perda de sentido com a combinação dos diferentes tipos de dados.

A utilização do Método AF para a análise da pobreza no município de Silveira Martins justifica-se não só pela possibilidade de identificação de quem são os multidimensionalmente pobres e em que medida a pobreza os assola, mas também pela flexibilidade na construção do instrumento de pesquisa, que se adapta ao contexto analisado, e pela possibilidade de decomposição da medida final em grupos, neste caso, bairros e faixas etárias.

\section{O MÉTODO AF EM SILVEIRA MARTINS-RS}

Na primeira fase deste trabalho, a técnica de pesquisa foi documentação indireta via pesquisa bibliográfica em diversas fontes de referências científicas, tais como livros, revistas e artigos científicos publicados em instituições como Programa das Nações Unidas para o Desenvolvimento, Banco Mundial e IPEA. Esta etapa da pesquisa teve o objetivo de entender o conceito de pobreza multidimensional proposto por Amartya Sen e o Método AF.

A segunda fase consiste no cálculo da medida de pobreza multidimensional para Silveira Martins/RS com o Método Alkire-Foster (2007) via pesquisa de campo. Para tanto, primeiramente foi aplicado um formulário teste para a identificação das dimensões de vida valoradas pela comunidade do município ${ }^{11}$. Baseado nos resultados obtidos com o primeiro formulário, foi 11 Sobre a identificação das dimensões de vida valoradas em Silveira Martins-RS, ver Marin et al (2013). 
elaborado o instrumento de pesquisa final, ferramenta que foi utilizada para a coleta dos dados deste estudo. $O$ tratamento dos dados e cálculo das medidas foi realizado com o Software Microsoft Excel (MICROSOFT, 2010). A seguir, são apresentados os 12 passos do Método AF aplicados ao município de Silveira Martins/RS.

\subsection{APLICAÇÃO DO MÉTODO ALKIRE-FOSTER}

O primeiro passo da metodologia AF consiste na definição da unidade de análise - as pessoas de Silveira Martins (RS). A escolha do município deu-se pelo fato de Silveira Martins ter um contingente populacional pequeno (2.449 habitantes em 2010, conforme dados do Atlas do Desenvolvimento Humano, de 2013), o que facilitou a realização deste estudo.

As dimensões de pobreza sob a perspectiva multidimensional não estão necessariamente vinculadas à renda, à educação ou à saúde, mas, sim, à expansão da capacitação dos indivíduos. Todavia, Sen (1979) não definiu uma lista de dimensões ou um método de identificação que deveria ser seguido. John Finnis (1980 apud ALKIRE, 2008) acredita que as dimensões valoradas podem ser identificadas através de um questionamento introspectivo sobre por que agir daquela maneira, isto é, perguntas como "por que eu faço isso?" ou "por que as pessoas agem dessa maneira?". Nessas situações, o indivíduo reflete sobre suas experiências de vida, crenças, relações e preferências de acordo com a cultura e a realidade em que vive. Dessa forma, ao se utilizar um instrumento de pesquisa baseado nos trabalhos de Barros, Carvalho e Franco (2006), Santos (2007) e Marin e Ottonelli (2008), foi possível definir as dimensões de maior relevância para as pessoas de Silveira Martins, via mecanismo participativo (ALKIRE; FOSTER, 2007).

A entrevista com 25 pessoas $^{12}$, com a utilização do primeiro formulário de pesquisa, permitiu a seleção de um grupo de dimensões de acordo com a realidade e a percepção das pessoas entrevistadas (SEN, 2004) e a construção de um instrumento definitivo adaptado às suas particularidades. Este instrumento está de acordo com o objetivo do Método AF de identificar quem são os multidimensionalmente pobres e o quão pobres estes o são, porém ele não deve ser reaplicado em outra unidade de análise, pois não refletiria as necessidades e percepções da nova unidade de estudo. Assim, o exercício de definição de dimensões deve ser refeito.

O levantamento junto aos entrevistados em Silveira Martins teve como intuito a investigação das razões ou dos valores básicos para suas ações por meio de um processo introspectivo de questionamento. Com base nessa primeira entrevista, as dimensões identificadas como mais valoradas foram as seguintes: 'saúde'; 'trabalho/renda'; 'habitação'; 'segurança'; 'educação'; 'acesso a serviços básicos'; 'preconceito'; 'comer adequadamente' e 'vida na comunidade'.

Após essa definição das dimensões ${ }^{13}$, via pesquisa de campo preliminar, a terceira fase da aplicação do Método AF compreendeu a definição dos indicadores para cada uma das dimensões apontadas como mais valoradas. O quadro 1 apresenta cada uma das nove dimensões com seus respectivos indicadores e linhas de corte.

12 Para maior profundidade sobre a aplicação desse primeiro formulário de pesquisa, que identificou as dimensões de vida valoradas, ver Marin et al (2013).

13 Para selecionar as dimensões, Alkire e Foster (2007) apresentam cinco mecanismos: o primeiro é o mecanismo de seleção, que é um exercício deliberativo ou participativo; o segundo é a utilização de uma lista que possua legitimidade e um tipo de consenso estável como, por exemplo, Direitos Humanos ou Objetivos de Desenvolvimento para o Milênio; o terceiro é baseado em uma teoria, como a de Martha Nussbaum, que estruturou um grupo de 10 capacitações; o quarto mecanismo consiste no uso de dados existentes; e o último é uma lista de comportamentos e preferências das pessoas com base em informação empírica, retiradas de estudos psicológicos, de pesquisas com consumidores ou de pesquisas de marketing. 
Quadro 1 - Dimensões, indicadores e linhas de corte

\begin{tabular}{|c|c|c|}
\hline Dimensões & Indicadores & Não Privado se... \\
\hline Saúde & $\begin{array}{l}\text { 1. IMC } \\
\text { 2. Horas de sono } \\
\text { 3. Vida estressante } \\
\text { 4. Atividade física } \\
\text { 5. Acesso a serviço de } \\
\text { saúde } \\
\text { 6. Atendimento médico } \\
\text { 7. Remédio } \\
\text { 8. Vício } \\
\text { 9. Condição de saúde } \\
\text { da família }\end{array}$ & $\begin{array}{l}\text { 1. IMC entre } 18 \text { e } 24,99 \mathrm{Kg} / \mathrm{cm}^{2} \\
\text { 2. } 6-8 \text { horas de sono } \\
\text { 3. Vida pouco estressante } \\
\text { 4. Pratica atividade física } \\
\text { 5. Tem acesso a serviços de saúde } \\
\text { 6. Nunca deixou de receber atendimento médico quando } \\
\text { precisou } \\
\text { 7. Sempre pode comprar um medicamento necessário } \\
\text { 8. Não possui vício } \\
\text { 9. As condições de saúde da família são boas ou ótimas }\end{array}$ \\
\hline Trabalho/renda & $\begin{array}{l}\text { 1. Emprego } \\
\text { 2. Horas trabalhadas } \\
\text { 3. Rendimento da casa } \\
\text { 4. Transferência gover- } \\
\text { namental }\end{array}$ & $\begin{array}{l}\text { 1. Possui emprego } \\
\text { 2. Trabalha até oito horas por dia } \\
\text { 3. Rendimento da casa superior a um salário mínimo } \\
\text { 4. Não recebe qualquer tipo de transferência governamental }\end{array}$ \\
\hline Habitação & $\begin{array}{l}\text { 1. Casa própria } \\
\text { 2. Equipamentos }\end{array}$ & $\begin{array}{l}\text { 1. Possui casa própria } \\
\text { 2. Possui geladeira, TV, rádio, fogão e chuveiro elétrico }\end{array}$ \\
\hline Segurança & $\begin{array}{l}\text { 1. Policiamento } \\
\text { 2. Violência }\end{array}$ & $\begin{array}{l}\text { 1. Existência de policiamento no seu bairro } \\
\text { 2. Não sofreu qualquer tipo de violência no bairro ou na ci- } \\
\text { dade }\end{array}$ \\
\hline Educação & $\begin{array}{l}\text { 1. Anos de estudo } \\
\text { 2. Estudar mais tempo } \\
\text { 3. Analfabetismo }\end{array}$ & $\begin{array}{l}\text { 1. Cursou, pelo menos, até a } 5^{\mathrm{a}} \text { série do Ensino Fundamenta } \\
\text { 2. Não gostaria de estudar mais, mas tem oportunidade } \\
\text { 3. Não há analfabetos na família }\end{array}$ \\
\hline $\begin{array}{l}\text { Acesso a serviços } \\
\text { básicos }\end{array}$ & 1. Serviços oferecidos & $\begin{array}{l}\text { 1. Tem acesso aos serviços de energia elétrica, possui água } \\
\text { encanada/tratada/poço, há coleta de lixo, drenagem para o } \\
\text { esgoto/poço negro e iluminação pública }\end{array}$ \\
\hline Preconceito & $\begin{array}{l}\text { 1. Discriminação } \\
\text { 2. Discriminação no } \\
\text { trabalho } \\
\text { 3. Esconder-se ou mu- } \\
\text { dar local de moradia } \\
\text { 4. Estar bem vestido } \\
\text { para ser respeitado } \\
\text { 5. Direitos garantidos }\end{array}$ & $\begin{array}{l}\text { 1. Ninguém da família sofreu qualquer tipo de discriminação } \\
\text { 2. Ser morador do local não foi empecilho para conseguir } \\
\text { emprego } \\
\text { 3. Não precisou se esconder ou mudar o local de moradia } \\
\text { para conseguir emprego } \\
\text { 4. Não acha necessário estar bem vestido para ser respeita- } \\
\text { do na comunidade ou fora dela } \\
\text { 5. Acha que tem seus direitos garantidos tanto quanto ou- } \\
\text { tros moradores da cidade }\end{array}$ \\
\hline $\begin{array}{l}\text { Comer adequada- } \\
\text { mente }\end{array}$ & $\begin{array}{l}\text { 1. Refeições } \\
\text { 2. Sentir-se bem ali- } \\
\text { mentado } \\
\text { 3. Diminuição da quan- } \\
\text { tidade de alimento } \\
\text { 4. Trocar alimentos por } \\
\text { mais baratos }\end{array}$ & $\begin{array}{l}\text { 1. Faz, pelo menos, três refeições por dia } \\
\text { 2. Sente-se sempre bem alimentado } \\
\text { 3. Nunca precisou diminuir a quantidade de alimentos por } \\
\text { falta de dinheiro } \\
\text { 4. Nunca precisou trocar os alimentos que consome por ali- } \\
\text { mentos mais baratos }\end{array}$ \\
\hline $\begin{array}{l}\text { Vida na comuni- } \\
\text { dade }\end{array}$ & $\begin{array}{l}\text { 1. Liberdade de opinar } \\
\text { na comunidade }\end{array}$ & 1. Sempre tem liberdade para opinar na comunidade \\
\hline
\end{tabular}

Fonte: Elaborado pelas autoras com base em instrumento definitivo de pesquisa.

A dimensão 'saúde' tem o intuito de observar o quão saudável as pessoas estão e a cobertura do acesso à saúde. Essa capacitação é relevante, pois serve como alicerce de expansão de outras capacitações. Por exemplo, uma pessoa saudável consegue inserção no mercado de trabalho e, com isso, acesso à renda, que é um meio de adquirir maior liberdade em relação àquilo que deseja.

A dimensão 'trabalho/renda' é relevante porque aquilo a que o indivíduo consegue ter acesso está limitado ao que ele ganha em termos monetários, e isso restringe sua liberdade de escolha dos itens. Assim, "uma pessoa pode trocar aquilo de que for proprietária por outro pa- 
cote de mercadorias" de valor monetário correspondente (SEN, 1999b, p. 15). A privação relativa de renda pode gerar uma privação absoluta de capacitações. Sen (1999b) argumenta que os direitos de troca dependem não somente do mercado, mas também, se houver, do Estado, que proporciona trocas como parte de seu programa social. Transferências de renda como seguro-desemprego, aposentadoria e benefícios específicos afetam os lotes de mercadorias que uma pessoa pode controlar. Segundo Sen (1999b), as provisões de segurança social são essenciais para o complemento dos processos de troca de mercado e de produção; são, ainda, particularmente importantes no contexto de carência alimentar.

As dimensões 'habitação' e 'acesso a serviços básicos' proporcionam às pessoas maior qualidade de vida. Um indivíduo com acesso a saneamento básico, por exemplo, tem menor possibilidade de ser contaminado por doenças e, portanto, consegue ter uma vida mais saudável. Da mesma forma, ter acesso a transporte público facilita a sua inserção no mercado de trabalho e a sua atuação na sociedade. Essas questões ganharam ainda mais destaque ao serem inseridas nos Objetivos de Desenvolvimento do Milênio, que defendem, entre outros, a universalização do abastecimento de água e do esgotamento sanitário. O Plano Nacional de Saneamento Básico (PLANSAB) estabeleceu metas e definiu montantes de investimentos para que elas sejam cumpridas até 2030 (OMD, 2014).

A dimensão 'segurança' é importante na medida em que a pobreza pode ser acentuada pela falta de segurança que o indivíduo sofre. Em muitos casos, bairros carentes e muito populosos têm maior incidência de violência, e isso pode acentuar a privação da liberdade dos moradores. As pessoas não se sentem seguras para sair de casa, isto é, têm sua liberdade restringida e não têm livre escolha para sair de casa no dia e/ou no horário que desejam. Caso o façam, podem ser vítimas de assaltos ou de outros tipos de crimes mais graves.

A dimensão 'educação' influencia a liberdade substantiva de o indivíduo ter uma vida melhor. Sen (1999a) defende que a falta de educação, no sentido de falta de acesso ao conhecimento escolar, age como uma barreira para a participação do indivíduo nas atividades econômicas. Além disso, uma pessoa com maior escolaridade tem maior consciência de como evitar riscos à saúde, e esse conhecimento proporciona uma vida mais saudável. Nesse sentido, a educação serve como alicerce para a expansão de outras liberdades.

As dimensões 'preconceito' e 'vida na comunidade' referem-se a privações do indivíduo em participar ativamente de sua comunidade, o que gera exclusão social. Para Sen (1999a), a necessidade de participar da vida na comunidade pode induzir a demanda por equipamentos modernos (como televisores, automóveis, entre outros) em um país no qual essas comodidades são quase universais, impondo uma pressão sobre as pessoas que são relativamente pobres. Obter esses equipamentos pode ser necessário para que o indivíduo seja aceito em determinado grupo. Da mesma forma, a própria pobreza pode representar uma restrição na liberdade das pessoas e gerar exclusão. Narayan (2000) identificou, nos pobres, esse sentimento de exclusão, pois eles têm consciência de sua falta de liberdade para expor suas ideias e sua vulnerabilidade. Por serem privados de participar de suas tradições, seus festejos e seus rituais, esses indivíduos são desestimulados a manter relações sociais.

A dimensão 'comer adequadamente' teve o intuito de observar um funcionamento básico na vida dos indivíduos, pois a "alimentação é o mais primitivo dos direitos" (SEN, 1999b, p. ??). Contudo há diferença entre sobreviver e estar bem nutrido. As pessoas que sobrevivem precisam estar suficientemente bem nutridas para viverem com dignidade e para cumprirem seus respectivos planos de vida (PNUD, 2010). Sendo assim, estar bem alimentado age como um suporte para a expansão das outras capacitações das pessoas. 
A definição dos indicadores, dentro de cada uma das dimensões e suas respectivas linhas de corte, teve por base pesquisas sobre pobreza a partir da Abordagem das Capacitações, bem como leitura e compreensão de literatura existente sobre o tema em estudo, destacando-se o trabalho de Alkire e Santos (2010), que serve de base para o cálculo do Índice de Pobreza Multidimensional (IPM), publicado no Relatório de Desenvolvimento Humano.

$\mathrm{O}$ instrumento definitivo de pesquisa, composto pelas nove dimensões e trinta e um indicadores, foi aplicado a 120 pessoas residentes em diferentes regiões (Bairro Centro, Vila Brasília e Bairro Linhas) de Silveira Martins nos meses de janeiro e fevereiro de $2012^{14}$. Das 120 pessoas entrevistas, 36 residem no Bairro Centro, 38 na Vila Brasília e 46 no Bairro Linhas. As informações obtidas por meio deste instrumento foram usadas nas etapas seguintes da pesquisa para c ćlculo das medidas de incidência $(H)$, da intensidade $(A)$ e da incidência ajustada da pobreza $\left({ }^{M_{0}}\right)$, propostas por Alkire e Foster (2007).

O quarto passo do Método AF consiste na definição da primeira linha de pobreza, ou seja, a determinação de um ponto de corte (que permite comparar entre o modo como a pessoa funciona de fato ao modo como ela deveria funcionar) para cada um dos indicadores considerados, conforme a terceira coluna do quadro 1, apresentado anteriormente. Nessa fase identificase, para cada um dos indicadores das dimensões definidas, se a pessoa é privada (P) ou não privada (NP). Por exemplo, no indicador de horas diárias trabalhadas, dentro da dimensão 'trabalho/ renda', se a pessoa trabalha até 8 horas diárias, ela é não privada; caso a carga de trabalho exceda esse limite, a pessoa é considerada privada.

Como exemplo, para os dez primeiros indivíduos, tem-se a matriz $X$ com a dimensão 'educação', com três indicadores: anos de estudo (A), analfabetismo (B) e estudar mais tempo (C). Conforme o quinto passo do Método AF, os indicadores dos indivíduos não privados (NP) recebem valor zero ( 0 ), enquanto os indicadores em que os indivíduos são considerados privados ( $P$ ) recebem valor um (1). Dessa forma, chega-se a matriz $g^{0}$. O próximo passo consiste na contagem das privações que cada indivíduo na amostra sofre, o que resulta na matriz c.

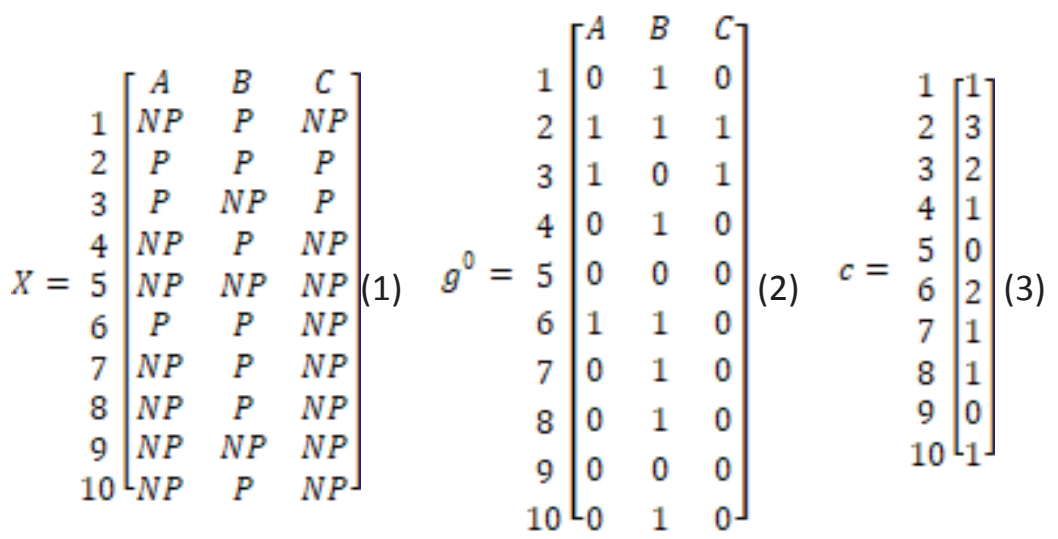

As privações de cada indivíduo são agregadas (sexto passo), ou seja, é obtida a soma de todos os indicadores que mostraram privação, como pode se observar na matriz c. Dessa forma, é possível visualizar, por exemplo, quais indicadores, dentro de cada dimensão, apresentam o maior número de pessoas privadas por unidade geográfica de análise.

14 O desenho amostral levou em consideração a amostragem para população finita e a necessidade de abranger os diferentes bairros da cidade. O tamanho da amostra foi definido a partir da estimação para população finita: margem de erro de $10 \%$, coeficiente de confiança de $95,5 \%$ na hipótese de p=0,5. A partir disso, a amostra estatisticamente significante seria de 96 pessoas, mas a pesquisa abrangeu 120 pessoas residentes e selecionadas aleatoriamente em três bairros da cidade. 
O quadro 2 mostra a quantidade de pessoas consideradas privadas por indicador e por região. As informações abaixo mostram que os indicadores com maior número de indivíduos privados são "estudar mais tempo", "trocar alimentos por mais baratos" e "atividade física", com 97,84 e 82 pessoas privadas, respectivamente. Os indicadores que apresentaram menos pessoas com privações foram "acesso a serviços de saúde", "esconder-se ou mudar local de moradia", "refeições"/"equipamentos" e "sentir-se bem alimentado", com nenhuma, três, seis e nove pessoas, respectivamente.

Quadro 2 - Número de privações por indicadores e por bairros

\begin{tabular}{|c|c|c|c|c|c|c|}
\hline \multirow[b]{2}{*}{ Dimensões } & \multirow[b]{2}{*}{ Indicadores } & \multicolumn{3}{|c|}{ Bairros } & \multirow[b]{2}{*}{ Total } & \multirow[b]{2}{*}{ Total $(\%$} \\
\hline & & Centro & Vila Brasília & Linhas & & \\
\hline \multirow{9}{*}{ Saúde } & 1. IMC & 4 & 15 & 10 & 29 & 0,24 \\
\hline & 2. Horas de sono & 18 & 12 & 20 & 50 & 0,42 \\
\hline & 3. Vida estressante & 7 & 8 & 24 & 39 & 0,33 \\
\hline & 4. Atividade física & 17 & 34 & 31 & 82 & 0,68 \\
\hline & 5. Acesso a serviço de saúde & 0 & 0 & 0 & 0 & 0,00 \\
\hline & 6. Atendimento médico & 3 & 9 & 5 & 17 & 0,14 \\
\hline & 7. Remédio & 6 & 17 & 14 & 37 & 0,31 \\
\hline & 8. Vício & 11 & 18 & 12 & 41 & 0,34 \\
\hline & 9. Condição de saúde da família & 10 & 13 & 20 & 43 & 0,36 \\
\hline \multirow{4}{*}{ Trabalho/renda } & 1. Emprego & 4 & 21 & 0 & 25 & 0,21 \\
\hline & 2. Horas trabalhadas & 6 & 20 & 16 & 42 & 0,35 \\
\hline & 3. Rendimento da casa & 2 & 19 & 6 & 27 & 0,23 \\
\hline & 4.Transferência governamental & 11 & 22 & 4 & 37 & 0,31 \\
\hline \multirow{2}{*}{ Habitação } & 1. Casa própria & 5 & 3 & 6 & 14 & 0,12 \\
\hline & 2. Equipamentos & 0 & 3 & 3 & 6 & 0,05 \\
\hline \multirow{2}{*}{ Segurança } & 1. Policiamento & 20 & 3 & 39 & 62 & 0,52 \\
\hline & 2. Violência & 3 & 11 & 3 & 17 & 0,14 \\
\hline \multirow{3}{*}{ Educação } & 1. Anos de estudo & 7 & 16 & 15 & 38 & 0,32 \\
\hline & 2. Estudar mais tempo & 27 & 29 & 41 & 97 & 0,81 \\
\hline & 3. Analfabetismo & 2 & 10 & 4 & 16 & 0,13 \\
\hline $\begin{array}{l}\text { Acesso a servi- } \\
\text { ços básicos }\end{array}$ & 1. Serviços oferecidos & 10 & 18 & 17 & 45 & 0,38 \\
\hline \multirow{5}{*}{ Preconceito } & 1. Discriminação & 7 & 13 & 10 & 30 & 0,25 \\
\hline & 2. Discriminação no trabalho & 27 & 3 & 11 & 41 & 0,34 \\
\hline & $\begin{array}{l}\text { 3. Esconder-se ou mudar local de } \\
\text { moradia }\end{array}$ & 2 & 1 & 0 & 3 & 0,03 \\
\hline & $\begin{array}{l}\text { 4. Estar bem vestido para ser respei- } \\
\text { tado }\end{array}$ & 10 & 21 & 18 & 49 & 0,41 \\
\hline & 5. Direitos garantidos & 10 & 26 & 21 & 57 & 0,48 \\
\hline \multirow{4}{*}{$\begin{array}{l}\text { Comer adequa- } \\
\text { damente }\end{array}$} & 1. Refeições & 1 & 5 & 0 & 6 & 0,05 \\
\hline & 2. Sentir-se bem alimentado & 3 & 3 & 3 & 9 & 0,08 \\
\hline & $\begin{array}{l}\text { 3. Diminuição da quantidade de ali- } \\
\text { mento }\end{array}$ & 6 & 16 & 14 & 36 & 0,30 \\
\hline & 4. Trocar alimentos por mais baratos & 26 & 27 & 31 & 84 & 0,70 \\
\hline $\begin{array}{l}\text { Vida na comu- } \\
\text { nidade }\end{array}$ & $\begin{array}{l}\text { 1. Liberdade de opinar na comunida- } \\
\text { de }\end{array}$ & 10 & 19 & 25 & 54 & 0,45 \\
\hline
\end{tabular}

Fonte: Elaborado pelas autoras com base em dados da pesquisa. 
Ao se considerarem as maiores privações por bairro, tem-se que no Centro os indicadores "estudar mais tempo", "discriminação no trabalho" e "trocar alimentos por mais baratos" possuem o maior número de pessoas privadas: 27,27 e 26, respectivamente. Na Vila Brasília, as maiores privações são em "atividade física", "estudar mais tempo", "trocar alimentos por mais baratos" e "direitos garantidos" com 34, 29, 27 e 26 indivíduos privados, respectivamente. Nas Linhas, no interior do município, "estudar mais tempo", "policiamento", "atividade física" e "trocar alimentos por mais baratos" revelaram-se os indicadores com maior número de indivíduos privados: $41,39,31$ e 31 .

Após a contagem de privações que cada pessoa apresenta, estabelece-se o segundo corte (sétimo passo), que consiste no número de indicadores $(k)$ em que uma pessoa deve ser privada para ser considerada multidimensionalmente pobre. Os indivíduos que não forem considerados pobres terão todos os seus indicadores com valor zero. Considerando o exemplo acima, da dimensão 'educação', o estabelecimento da segunda linha de corte como 2 resultará na matriz $g^{0}(k=2)$.

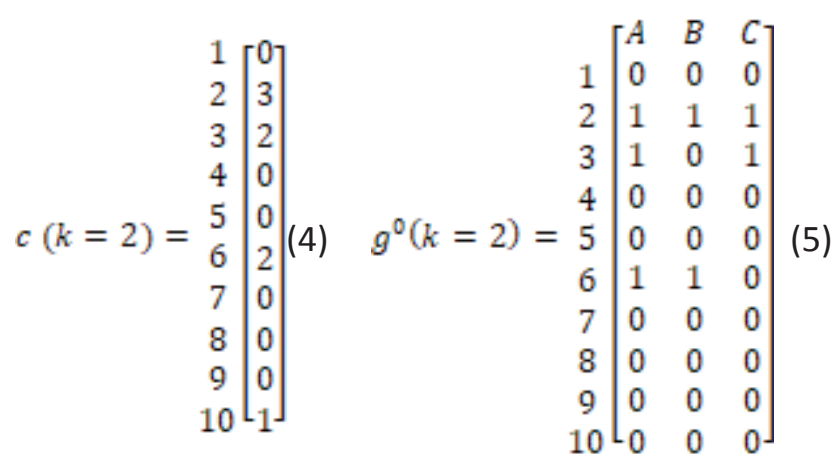

Primeiramente substitui-se $\mathrm{P}$ e NP, conforme a matriz $\mathrm{X}$, por 1 e por 0 , respectivamente. O próximo passo é fazer o somatório das privações que cada indivíduo sofre, o que resulta na matriz c. A seguir, aplica-se a linha de corte $k$ (oitavo passo), que, para o exemplo, foi definida como 2. Para construção da matriz $g^{0}(k=2)$, os indivíduos que têm dois ou mais funcionamentos não atendidos são multidimensionalmente pobres e, por isso, recebem valor 1 . Já as pessoas que sofrem privação em menos de dois funcionamentos, recebem valor 0 para todas as suas privações, isto é, são desconsideradas, como mostra a matriz c ( $k=2)$.

De acordo com o nono passo do Método AF, para cada valor de $k$ é calculado a percentagem de pobres em relação ao total de pessoas, ou seja, o Headcount, conforme a equação 6 a seguir:

$$
H=q / n(6)
$$

Em que:

$\mathrm{H}=$ Headcount;

$q$ = número de pessoas multidimensionalmente pobres;

$n=$ número total de pessoas;

Para obter $q$, deve-se considerar o segundo corte, que, de acordo com o exemplo acima, é 2. Seguindo o exemplo da dimensão 'educação' para os primeiros 10 indivíduos entrevistados, são três pessoas multidimensionalmente pobres para uma amostra de dez pessoas. Nesse caso, a incidência de pobreza seria de 0,3 , ou seja, $30 \%$ das pessoas são multidimensionalmente pobres.

O décimo passo consiste no cálculo da pobreza média (A), que mostra a média da fração 
de dimensões que os indivíduos são privados. Se $A=0,5$, isso significa que, em média, as pessoas são privadas em $50 \%$ das dimensões/dos indicadores considerados. Se $A=1$, indica que todos os multidimensionalmente pobres são privados em $100 \%$ das dimensões/dos indicadores analisados (GALLO; ROCHE, 2012). Para determinar A, foi necessário encontrar a soma das razões do número de privações de cada pessoa pobre e o total de indicadores, e o resultado foi dividido pelo total de pessoas.

O passo seguinte, décimo primeiro, resulta no cálculo da incidência ajustada de pobreza $\left(\mathrm{M}_{0}\right)$, encontrada por meio da multiplicação da pobreza média $A$ pela incidência da pobreza $\mathrm{H}$ $(\mathrm{H} \times \mathrm{A})$. $\mathrm{O} \mathrm{M}_{0}{ }^{15}$ é sensível tanto à frequência quanto à intensidade da pobreza, isto é, as variações no número de pobres e/ou no número de indicadores que uma pessoa sofre privação provocam alterações na medida final (GALLO; ROCHE, 2012). A incidência ajustada da pobreza, conforme Gallo e Roche (2012), é interpretada como a proporção de privações que a população pobre enfrenta em relação ao número máximo das privações que toda a população poderia sofrer. Quando $M_{0}=1$, ou, em termos percentuais, igual a $100 \%$, toda a população é pobre e é privada nas dimensões e nos indicadores considerados.

Por fim, as medidas de incidência e de intensidade da pobreza foram decompostas por região (bairro) do município de Silveira Martins/RS (décimo segundo passo). Ressalta-se que os quatro últimos passos do Método AF são especificados e demonstrados na próxima seção.

\section{DISCUSSÃO DOS RESULTADOS: M0}

Os últimos quatro passos do Método AF consistem em gerar as medidas de incidência de pobres $(\boldsymbol{H})$ de intensidade da pobreza ou pobreza média (A), de incidência ajustada pela intensidade $\left({ }^{\mathrm{M}_{0}}\right)$ e decompostas por grupos. É importante ressaltar que não há um valor padrão para o segundo corte $(k)$, embora este não possa estar nos extremos. Se considerar o $k$ igual a 22 , não há pessoas que sofram privações, isto é, não há pobres em termos multidimensionais. Contudo, se $k$ for igual a 1 , todas as pessoas entrevistadas serão privadas ( $100 \%$ doc indivíduos serão multidimensionalmente pobres), ou seja, quanto maior o valor do $k$, menor o ${ }^{M_{0}}$. Abaixo, na tabela 1, são apresentados os resultados agregados correspondentes aos passos 7 a 11 do Método AF para a amostra considerada neste trabalho.

Tabela 1 - Pobreza multidimensional no município de Silveira Martins para $k$ indicadores

\begin{tabular}{c|c|c|c|c|c}
\hline $\boldsymbol{k}$ & $\begin{array}{c}\text { Total de } \\
\text { Pessoas }\end{array}$ & \multicolumn{1}{c}{ No de pobres } & \multicolumn{1}{c}{ Headcount $(\mathbf{H})$} & \multicolumn{1}{c}{ Pobreza Média (A) } & $\begin{array}{c}\text { Incidência ajustada } \\
(\mathbf{M} \mathbf{0})=\mathbf{H}^{*} \mathbf{A}\end{array}$ \\
\hline $\mathbf{5}$ & 120 & 104 & 0,87 & 0,34 & 0,29 \\
\hline $\mathbf{6}$ & 120 & 99 & 0,83 & 0,35 & 0,29 \\
\hline $\mathbf{7}$ & 120 & 87 & 0,73 & 0,37 & 0,27 \\
\hline $\mathbf{8}$ & 120 & 75 & 0,63 & 0,39 & 0,24 \\
\hline $\mathbf{9}$ & 120 & 65 & 0,54 & 0,41 & 0,22 \\
\hline $\mathbf{1 0}$ & 120 & 53 & 0,44 & 0,44 & 0,19 \\
\hline $\mathbf{1 1}$ & 120 & 45 & 0,38 & 0,46 & 0,17 \\
\hline $\mathbf{1 2}$ & 120 & 39 & 0,33 & 0,47 & 0,15 \\
\hline $\mathbf{1 3}$ & 120 & 30 & 0,25 & 0,50 & 0,12 \\
\hline $\mathbf{1 4}$ & 120 & 18 & 0,15 & 0,55 & 0,08 \\
\hline $\mathbf{1 5}$ & 120 & 14 & 0,12 & 0,57 & 0,07 \\
\hline
\end{tabular}

Fonte: Elaborada pelas autoras com base em dados da pesquisa.

$150 \mathrm{M}_{0}$ pode ser decomposto para cada subgrupo da população. Depois disso, pode-se analisar a contribuicão de cada dimensão para a pobreza geral. A é dividido pelos pobres na dimensão j, resultando em $A_{j^{\prime}}$ que, multiplicado por $\mathrm{H}_{\text {, leva a }} \mathrm{M}_{0 \mathrm{j}}$, a dimensão ajustada que mostra a participação da dimensão j na pobreza global. 
Os resultados da tabela 1 referem-se a diferentes valores de $k(k=5, \ldots, 15)$. De acordo com cada um desses valores, foram obtidos os respectivos números de pobres, a incidência da pobreza $(H)$, a intensidade da pobreza $(A)$ e a incidência ajustada $\left(M_{0}\right)$.

Na medida geral, adotando-se $k=6$, o número de pessoas pobres, indicado pelo $\mathrm{H}$, é igual a 99, ou seja, $83 \%$ da amostra é multidimensionalmente pobre. Pode-se observar que, no caso de Silveira Martins, as maiores privações não são monetárias. O quadro 2 mostra que os indicadores com maiores privações estão relacionados com as dimensões 'educação' (81\% da amostra é privada no indicador "estudar por mais tempo"), 'comer adequadamente' (70\% da amostra é privada no indicador "trocar alimentos por mais baratos"), 'saúde' (68\% da amostra é privada no indicador "atividade física") e 'segurança' ( $52 \%$ da amostra é privada no indicador policiamento). Isso indica que medir a pobreza exclusivamente com base na renda, como o usual, seria subestimar a taxa de pobreza, ou seja, as maiores privações estão em outros aspectos da vida das pessoas e não necessariamente na carência monetária. Se forem comparadas a incidência da pobreza multidimensional $(\mathrm{H})$ e a incidência da pobreza unidimensional, em termos de renda ${ }^{16}$, observa-se que há uma diferença de 60,5 pontos percentuais entre os índices. $O$ cálculo da incidência de pobreza unidimensional monetária mostra que $22,5 \%$ dos indivíduos da amostra têm renda familiar total menor que um salário mínimo.

A pobreza média (A), que mede a intensidade da pobreza, indica, para o mesmo valor de $k=6$, que as pessoas apresentam, em média, privação em $35 \%$ dos 31 indicadores considerados na pesquisa. A incidência ajustada mostra a pobreza multidimensional ajustada a sua intensidade, ou seja, o indicador $\mathrm{M}_{0}$ aumentará caso os pobres sejam privados em um conjunto maior de indicadores. A medida geral $\left(\mathrm{M}_{0}\right)$ encontrada para o município de Silveira Martins foi de 0,29. Isso significa que o total de indicadores em que os pobres sofrem privação representa $29 \%$ do máximo possível na amostra em estudo.

Quando se analisa a medida desagregada por região (passo 12 do Método AF), têm-se os resultados mostrados na tabela 2 .

Tabela 2 - Pobreza multidimensional no município de Silveira Martins, por região, para $k$ indicadores

\begin{tabular}{|c|c|c|c|c|c|c|c|c|c|c|c|c|c|c|c|c|c|}
\hline \multicolumn{6}{|c|}{ BAIRRO CENTRO } & \multicolumn{6}{|c|}{ BAIRRO VILA BRASÍLIA } & \multicolumn{6}{|c|}{ BAIRRO LINHAS } \\
\hline$k$ & $\begin{array}{l}\text { Total de } \\
\text { Pessoas }\end{array}$ & $\begin{array}{c}\text { № de } \\
\text { pobres }\end{array}$ & H & A & MO & $k$ & $\begin{array}{l}\text { Total de } \\
\text { Pessoas }\end{array}$ & $\begin{array}{l}\text { № de } \\
\text { pobres }\end{array}$ & H & A & Mo & $k$ & $\begin{array}{l}\text { Total de } \\
\text { Pessoas }\end{array}$ & $\begin{array}{l}\text { № de } \\
\text { pobres }\end{array}$ & H & A & Mo \\
\hline 5 & 36 & 26 & 0,72 & 0,27 & 0,20 & 5 & 38 & 37 & 0,97 & 0,40 & 0,39 & 5 & 46 & 41 & 0,89 & 0,32 & 0,28 \\
\hline 6 & 36 & 22 & 0,61 & 0,29 & 0,18 & 6 & 38 & 37 & 0,97 & 0,40 & 0,39 & 6 & 46 & 40 & 0,87 & 0,32 & 0,28 \\
\hline 7 & 36 & 16 & 0,44 & 0,33 & 0,15 & 7 & 38 & 34 & 0,89 & 0,42 & 0,38 & 7 & 46 & 37 & 0,80 & 0,33 & 0,27 \\
\hline 8 & 36 & 14 & 0,39 & 0,34 & 0,13 & 8 & 38 & 31 & 0,82 & 0,44 & 0,36 & 8 & 46 & 30 & 0,65 & 0,36 & 0,23 \\
\hline 9 & 36 & 10 & 0,28 & 0,37 & 0,10 & 9 & 38 & 30 & 0,79 & 0,45 & 0,35 & 9 & 46 & 25 & 0,54 & 0,38 & 0,21 \\
\hline 10 & 36 & 6 & 0,17 & 0,43 & 0,07 & 10 & 38 & 28 & 0,74 & 0,46 & 0,34 & 10 & 46 & 19 & 0,41 & 0,41 & 0,17 \\
\hline 11 & 36 & 4 & 0,11 & 0,48 & 0,05 & 11 & 38 & 26 & 0,68 & 0,47 & 0,32 & 11 & 46 & 15 & 0,33 & 0,43 & 0,14 \\
\hline 12 & 36 & 4 & 0,11 & 0,48 & 0,05 & 12 & 38 & 22 & 0,58 & 0,49 & 0,28 & 12 & 46 & 13 & 0,28 & 0,44 & 0,12 \\
\hline 13 & 36 & 3 & 0,08 & 0,52 & 0,04 & 13 & 38 & 19 & 0,50 & 0,50 & 0,25 & 13 & 46 & 8 & 0,17 & 0,47 & 0,08 \\
\hline 14 & 36 & 2 & 0,06 & 0,56 & 0,03 & 14 & 38 & 12 & 0,32 & 0,55 & 0,17 & 14 & 46 & 4 & 0,09 & 0,52 & 0,05 \\
\hline 15 & 36 & 1 & 0,03 & 0,68 & 0,02 & 15 & 38 & 10 & 0,26 & 0,57 & 0,15 & 15 & 46 & 3 & 0,07 & 0,55 & 0,04 \\
\hline
\end{tabular}

Fonte: Elaborada pelas autoras com base em dados da pesquisa.

16 A incidência unidimensional monetária foi calculada através da divisão do número de privados no indicador renda - domicílio que aufere menos que um salário mínimo na data de coleta dos dados - pelo total da amostra - 120 pessoas entrevistadas. 
Os resultados da medida $\mathrm{M}_{0}$, mostrados na tabela 2, para os diversos $k$ revelam que a Vila Brasília possui a maior incidência ajustada de pobreza, acima da média geral para o município de Silveira Martins (RS), enquanto o bairro Centro possui o menor resultado em tal medida, seguido das Linhas, ambos, respectivamente, abaixo da média. Com $k$ igual a 5 , das 38 pessoas da Vila Brasília, 97\% são multidimensionalmente pobres e apresentam, em média, privação em 40\% dos 31 indicadores considerados. Já na região central, dos 36 entrevistados, $72 \%$ são pobres em nível mutidimensional e apresentam em média privação em $29 \%$ dos 31 indicadores. No bairro Linhas, das 46 pessoas ouvidas, $89 \%$ são multidimensionalmente pobres e apresentam em média privação em $32 \%$ dos 31 indicadores considerados na pesquisa.

A incidência de pobreza por meio da variável renda é de 50\%, 5,55\% e 13,04\% da amostra pobre na Vila Brasília, Centro e Linhas, respectivamente. Percebe-se, ao comparar a incidência de pobreza multidimensional e a de pobreza monetária, que há uma subestimação das taxas de pobreza, visto que a pobreza se apresenta muito mais intensa quando consideradas outras dimensões além da renda. A Vila Brasília, em uma perspectiva multidimensional, apresenta a maior incidência de pobreza via renda (50\%), mas é ainda maior se vista pela perspectiva da multidimensionalidade (97\%). As maiores privações dos moradores da Vila Brasília estão relacionadas às dimensões 'saúde' (89,47\% da amostra é privada no indicador "atividade física"), 'educação' (76,31\% da amostra é privada no indicador "estudar mais tempo") e 'preconceito' (68,42\% da amostra é privada no indicador "direitos garantidos").

No bairro Linhas, que inclui as regiões interioranas do município, também foi possível observar uma subestimação da pobreza, se vista unicamente atrelada à renda monetária, com uma diferença de 75,6 pontos percentuais entre as estimações das incidências de pobreza uni e multidimensional. As maiores privações da amostra, neste bairro, estão relacionadas com 'educação' (89,13\% da amostra é privada no indicador "estudar mais tempo"), com 'segurança' (84,78\% da amostra é privada no indicador "segurança") e com 'saúde' e 'comer adequadamente' (67,39\% da amostra é privada nos indicadores "atividade física" e "trocar alimentos por mais baratos").

A região central tem a menores incidências de pobreza do município, tanto uni como multidimensionalmente. Ainda assim, é possível observar que as maiores privações também não estão na carência de renda monetária, mas, sim, em outros aspectos da vida da população. As maiores privações estão nas dimensões 'preconceito', 'educação' - nas quais 75\% da amostra é privada nos indicadores "discriminação no trabalho" e "estudar mais tempo" -, 'comer adequadamente' - em que $72,22 \%$ é privada no indicador "trocar alimentos por mais baratos" - e 'segurança' - na qual 55,55\% da amostra é privada no indicador "policiamento".

Esses resultados indicam que as pessoas que moram em diferentes localidades apresentam privações diferenciadas. Nesse sentido, em termos de implicação para as políticas públicas de combate à pobreza, o Método AF auxilia na formulação de políticas focadas não somente nas privações que a amostra de Silveira Martins apresentou, mas também na elaboração de soluções mais específicas para as privações de cada bairro.

Nas tabelas seguintes são apresentados os resultados por faixa etária, conforme os cinco últimos passos do Método $\mathrm{AF}$, descritos anteriormente. Os resultados referem-se a diferentes valores de $k(n=5, \ldots, 15)$. Para cada um desses valores, foram obtidas a quantidade de indivíduos pobres, a incidência da pobreza $(H)$, a pobreza média $(A)$ e a incidência ajustada $(H \times A)$. 
Tabela 3 - Pobreza multidimensional no município de Silveira Martins para $k$ indicadores para faixa etária de até 25 anos e de 26 a 35 anos.

\begin{tabular}{c|c|c|c|c|c|c|c|c|c|c}
\hline \multicolumn{5}{c|}{ Faixa etária: até 25 anos } & \multicolumn{5}{c|}{ Faixa etária: 26 a 35 anos } \\
\hline $\boldsymbol{k}$ & $\begin{array}{c}\text { Total de } \\
\text { Pessoas }\end{array}$ & $\begin{array}{c}\text { No de } \\
\text { pobres }\end{array}$ & H & A & Mo & $\begin{array}{c}\text { Total de } \\
\text { Pessoas }\end{array}$ & $\begin{array}{c}\text { No de } \\
\text { pobres }\end{array}$ & H & A & M0 \\
\hline $\mathbf{5}$ & 14 & 14 & 1,000 & 0,339 & 0,339 & 18 & 14 & 0,778 & 0,406 & 0,315 \\
\hline $\mathbf{6}$ & 14 & 13 & 0,929 & 0,352 & 0,327 & 18 & 14 & 0,778 & 0,406 & 0,315 \\
\hline $\mathbf{7}$ & 14 & 10 & 0,714 & 0,400 & 0,286 & 18 & 13 & 0,722 & 0,422 & 0,305 \\
\hline $\mathbf{8}$ & 14 & 8 & 0,571 & 0,444 & 0,253 & 18 & 12 & 0,667 & 0,438 & 0,292 \\
\hline $\mathbf{9}$ & 14 & 8 & 0,571 & 0,444 & 0,253 & 18 & 12 & 0,667 & 0,438 & 0,292 \\
\hline $\mathbf{1 0}$ & 14 & 8 & 0,571 & 0,444 & 0,253 & 18 & 10 & 0,556 & 0,468 & 0,260 \\
\hline $\mathbf{1 1}$ & 14 & 7 & 0,500 & 0,461 & 0,230 & 18 & 9 & 0,500 & 0,484 & 0,242 \\
\hline $\mathbf{1 2}$ & 14 & 6 & 0,429 & 0,478 & 0,205 & 18 & 9 & 0,500 & 0,484 & 0,242 \\
\hline $\mathbf{1 3}$ & 14 & 6 & 0,429 & 0,478 & 0,205 & 18 & 7 & 0,389 & 0,512 & 0,199 \\
\hline $\mathbf{1 4}$ & 14 & 3 & 0,214 & 0,538 & 0,115 & 18 & 5 & 0,278 & 0,548 & 0,152 \\
\hline $\mathbf{1 5}$ & 14 & 2 & 0,143 & 0,581 & 0,083 & 18 & 4 & 0,222 & 0,573 & 0,127 \\
\hline
\end{tabular}

Fonte: Elaborada pelas autoras com base em dados da pesquisa.

A tabela 3 mostra os resultados da aplicação do Método AF para as faixas etárias de até 25 anos (total de 14 pessoas) e de 26 a 35 anos (total de 18 pessoas). Na primeira faixa etária, 0 número de pessoas pobres passa de $14(k=5)$ para $2(k=15)$. O número médio de privações por pessoa passa de $33,9 \%(k=5)$ para $58,1 \%$ dos 31 indicadores $(k=15)$. 0 total de indicadores em que os pobres têm limitação representam $33,9 \%(k=5)$ e $8,3 \%(k=15)$ do máximo de pobreza que esta parcela da amostra poderia sofrer, considerando as respectivas linhas de corte. Na segunda faixa etária, o número de pessoas pobres passa de $14(k=5)$ para $4(k=15)$. O número médio de privações $n \cap r$ pessoa passa de 40,6\% $(k=5)$ para $57,3 \%$ dos 31 indicadores $(k=15)$. A incidência ajustada $\left({ }^{M_{0}}\right)$ varia de $0,315(k=5)$ a 0,127 ( $\left.k=15\right)$, isto é, o total de indicadores em que os pobres dessa segunda faixa etária sofrem privação representa 31,5\% e 12,7\% do máximo possível na amostra em estudo, nas respectivas linhas de corte.

Ao adotar um valor para $k$ mediano (igual a 6), 93\% da amostra é multidimensionalmente pobre, e o percentual de privações que essas pessoas sofrem é de $35,2 \%$ dos indicadores, em média, para a faixa etária de até 25 anos. Já para a faixa etária de 26 a 35 anos, a incidência da pobreza é menor: $77,8 \%$ da amostra é multidimensionalmente pobre, sendo privados, em média, em 40,6\% dos 31 indicadores. Ressalta-se que, embora nessa última faixa etária haja menor incidência de pobreza, os indivíduos são privados em um maior número de indicadores que os da primeira faixa.

Tabela 4 - Pobreza multidimensional no município de Silveira Martins para $k$ indicadores para faixa etária de 36 a 45 anos e 46 a 59 anos

\begin{tabular}{c|c|c|c|c|c|c|c|c|c|c}
\hline \multicolumn{7}{c|}{ Faixa etária: 36 a 45 anos } & \multicolumn{5}{c}{ Faixa etária: 46 a 59 anos } \\
\hline $\boldsymbol{k}$ & $\begin{array}{c}\text { Total de } \\
\text { Pessoas }\end{array}$ & $\begin{array}{c}\text { No de } \\
\text { pobres }\end{array}$ & $\mathbf{H}$ & $\mathbf{A}$ & $\mathbf{M 0}$ & $\begin{array}{c}\text { Total de } \\
\text { Pessoas }\end{array}$ & $\begin{array}{c}\text { No de } \\
\text { pobres }\end{array}$ & $\mathbf{H}$ & $\mathbf{A}$ & Mo \\
\hline $\mathbf{5}$ & 15 & 12 & 0,800 & 0,282 & 0,226 & 34 & 32 & 0,941 & 0,338 & 0,318 \\
\hline $\mathbf{6}$ & 15 & 12 & 0,800 & 0,282 & 0,226 & 34 & 30 & 0,882 & 0,349 & 0,308 \\
\hline $\mathbf{7}$ & 15 & 10 & 0,667 & 0,300 & 0,200 & 34 & 28 & 0,824 & 0,361 & 0,297 \\
\hline $\mathbf{8}$ & 15 & 7 & 0,467 & 0,332 & 0,155 & 34 & 24 & 0,706 & 0,383 & 0,270 \\
\hline $\mathbf{9}$ & 15 & 4 & 0,267 & 0,387 & 0,103 & 34 & 20 & 0,588 & 0,408 & 0,240 \\
\hline $\mathbf{1 0}$ & 15 & 3 & 0,200 & 0,419 & 0,084 & 34 & 17 & 0,500 & 0,429 & 0,214 \\
\hline $\mathbf{1 1}$ & 15 & 2 & 0,133 & 0,468 & 0,062 & 34 & 14 & 0,412 & 0,452 & 0,186 \\
\hline
\end{tabular}




\begin{tabular}{l|l|l|l|l|l|l|l|l|l|l}
\hline $\mathbf{1 2}$ & 15 & 2 & 0,133 & 0,468 & 0,062 & 34 & 12 & 0,353 & 0,468 & 0,165 \\
\hline $\mathbf{1 3}$ & 15 & 2 & 0,133 & 0,468 & 0,062 & 34 & 9 & 0,265 & 0,495 & 0,131 \\
\hline $\mathbf{1 4}$ & 15 & 1 & 0,067 & 0,516 & 0,034 & 34 & 5 & 0,147 & 0,555 & 0,082 \\
\hline $\mathbf{1 5}$ & 15 & 1 & 0,067 & 0,516 & 0,034 & 34 & 4 & 0,118 & 0,581 & 0,068 \\
\hline
\end{tabular}

Fonte: Elaborada pelas autoras com base em dados da pesquisa.

A tabela 4 mostra os resultados para as faixas etárias de 36 a 45 anos (15 pessoas) e 46 a 59 anos (34 pessoas). Na primeira faixa etária, $M_{0}$ varia de 0,226 a 0,034. Já na segunda faixa etária, percebe-se uma variação de 0,318 a 0,068. A segunda faixa etária tem um $\mathrm{M}_{0}$ maior para todos os valores de $k$, o que indica haver privação mais intensa quanto maior for o número de indicadores. Ao adotar um valor de $k=6$ para a faixa de 36 a 45 anos, $80 \%$ da amostra é multidimensionalmente pobre, em média, em $28,2 \%$ dos indicadores. Com o mesmo valor de $k$, na faixa etária de 46 a 59 anos $88,2 \%$ da amostra é considerada multidimensionalmente pobre, em média, em $34,9 \%$ dos indicadores. Pode-se observar que a incidência, a pobreza média e o $M_{0}$ apresentam valores maiores para a última faixa etária.

Tabela 5 - Pobreza multidimensional no município de Silveira Martins para $k$ indicadores para faixa etária de 60 anos ou mais.

\begin{tabular}{c|c|c|c|c|c}
\hline \multicolumn{7}{c}{ Faixa etária: $\mathbf{6 0}$ ou mais } \\
\hline $\boldsymbol{k}$ & Total de Pessoas & No de pobres & $\mathbf{H}$ & $\mathbf{A}$ & M0 \\
\hline 5 & 39 & 32 & 0,821 & 0,324 & 0,266 \\
\hline 6 & 39 & 30 & 0,769 & 0,334 & 0,257 \\
\hline 7 & 39 & 26 & 0,667 & 0,356 & 0,237 \\
\hline 8 & 39 & 24 & 0,615 & 0,367 & 0,226 \\
\hline 9 & 39 & 21 & 0,538 & 0,382 & 0,206 \\
\hline 10 & 39 & 15 & 0,385 & 0,419 & 0,161 \\
\hline 11 & 39 & 13 & 0,333 & 0,434 & 0,145 \\
\hline 12 & 39 & 10 & 0,256 & 0,458 & 0,117 \\
\hline 13 & 39 & 6 & 0,154 & 0,505 & 0,078 \\
\hline 14 & 39 & 4 & 0,103 & 0,548 & 0,056 \\
\hline 15 & 39 & 3 & 0,077 & 0,581 & 0,045 \\
\hline
\end{tabular}

Fonte: Elaborada pelas autoras com base em dados da pesquisa.

A tabela 5 mostra os resultados do Método AF para a faixa etária de 60 anos ou mais (total de 39 pessoas). Adotando-se $k=6$, observa-se que 76,9\% da amostra é multidimensionalmente pobre, sendo privados, em média, em $33,4 \%$ dos indicadores. $O$ total de indicadores em que os pobres sofrem privação representa $25,7 \%$ do máximo possível na amostra.

Na comparação das diferentes faixas etárias consideradas para um valor de $k=6$, a faixa etária que apresenta maior incidência ajustada de pobreza é a de até 25 anos, com um valor de 0,327 , isto é, o total de indicadores em que os pobres desta faixa etária sofrem privação representa $32,7 \%$ do máximo possível neste grupo, sendo que $92,9 \%$ das pessoas desta faixa são multidimensionalmente pobres e possuem privações, em média, em 35,2\% dos 31 indicadores.

Na faixa etária de até 25 anos de idade, as maiores privações estão nas dimensões 'preconceito' (85,71\% da amostra é privada no indicador "direitos garantidos"), 'segurança' e 'comer adequadamente' (78,57\% da amostra é privada no indicador "violência" e "trocar alimentos por mais baratos") e 'saúde' (71,42\% da amostra é privada no indicador "atividade física").

As maiores privações da faixa etária de 26 a 35 anos estão ligadas às dimensões 'segurança' (83,33\% da amostra é privada no indicador "policiamento"), 'educação' e 'comer adequadamente' (77,78\% da amostra é privada nos indicadores "estudar mais tempo" e "trocar alimen- 
tos por mais baratos"), 'saúde' e 'preconceito' (61,11\% da amostra é privada nos indicadores "atividade física" e "direitos garantidos").

Na faixa etária de 36 a 45 anos, as maiores privações estão atreladas às dimensões 'educação' ( $73,33 \%$ da amostra é privada no indicador "estudar mais tempo"), 'segurança', 'comer adequadamente' e 'saúde' (66,67\% da amostra é privada nos indicadores "policiamento", "trocar alimentos por mais baratos" e "atividade física").

$\mathrm{Na}$ amostra de 46 a 60 anos de idade, as maiores privações estão relacionadas às dimensões 'educação' e 'segurança' (82,35\% da amostra é privada nos indicadores "estudar mais tempo" e "policiamento"), 'comer adequadamente' (74,47\% da amostra é privada no indicador "trocar alimentos por mais baratos") e 'saúde' (67,65\% da amostra é privada no indicador "atividade física").

Por fim, na faixa etária de mais de 60 anos, as maiores privações estão nas dimensões 'educação' (92,31\% da amostra é privada no indicador "estudar por mais tempo"), 'saúde' e 'segurança' (71,79\% da amostra é privada nos indicadores "atividade física" e "policiamento") e 'comer adequadamente' (58,97\% da amostra é privada no indicador "trocar alimentos por mais baratos").

É possível perceber que, em nenhum dos bairros ou nas diferentes faixas etárias, as maiores privações estão vinculadas à carência de renda monetária; ao contrário, se relacionam principalmente à saúde, à segurança e à educação. Isso explica por que a mensuração da pobreza unicamente através da renda é subestimada: ao se inserir outros aspectos da vida das pessoas na medição, é possível captar várias privações ignoradas e, com isso, a incidência de pobreza aumenta. Percebe-se que, para todas as faixas etárias, a incidência de pobreza via renda é menor do que o H. Como as maiores privações da amostra não estão em indicadores ligados à renda, a pobreza é mais intensa ao se inserir outras variáveis. A tabela 6 mostra as diferenças para as diversas faixas etárias analisadas.

Tabela 6 - Comparação entre a incidência de pobreza multidimensional $(k=6)$ e unidimensional (renda)

\begin{tabular}{c|c|c|c}
\hline Faixa etária & Headcount $(\mathbf{H})$ & Incidência via renda & $\begin{array}{c}\text { Diferença } \\
\text { percentual }\end{array}$ \\
\hline Até 25 anos de idade & 92,86 & 21,42 & 71,44 \\
\hline 26 a 35 anos & 77,78 & 38,89 & 38,89 \\
\hline 36 a 45 anos & 80,00 & 26,67 & 53,33 \\
\hline 46 a 60 anos & 88,24 & 26,47 & 61,77 \\
\hline mais de 60 anos & 76,92 & 10,25 & 66,67 \\
\hline
\end{tabular}

Fonte: Elaborada pelas autoras com base em dados da pesquisa.

A maior diferença está na faixa etária de até 25 anos de idade, com 71,44 pontos percentuais, seguido pela faixa etária de mais de 60 anos, com 66,67 pontos percentuais. Já a menor diferença entre as incidências de pobreza uni e multidimensional está na faixa etária de 26 a 35 anos, com 38,89 pontos percentuais. A importância de conhecer a localidade (como bairros), pessoas (faixas etárias) e os tipos de privações que afetam a vida desses indivíduos é importante para o planejamento de políticas públicas focadas diretamente nas diferentes pobrezas de uma determinada população.

Destaca-se que medir a pobreza somente pela renda não proporciona uma maior diversidade de informações para o planejamento público de ações focadas em aliviar as várias faces que a pobreza assume em locais específicos. Por exemplo, o bairro com maior incidência de pobreza é Vila Brasília; sabendo-se que as maiores privações nesse bairro são em relação à 'educação', à 'saúde' e ao 'preconceito', é possível realizar políticas públicas que priorizem esses 
aspectos. Até mesmo através de dados desagregados, como a faixa etária, a medida multidimensional permite que sejam estabelecidos programas específicos para públicos-alvo, como programas voltados a aspectos qualitativos de saúde, alimentação, segurança, educação e de manutenção do bem-estar das pessoas com mais de 60 anos. A análise da pobreza através de suas várias dimensões proporciona uma diversidade informacional que é importante para a formulação das políticas públicas e que estimula o desenvolvimento humano e econômico (local e regional).

\section{CONSIDERAÇÕES FINAIS}

Este estudo de identificação e mensuração da pobreza, realizado em Silveira Martins com base no Método AF, possibilita que sejam desenvolvidas políticas voltadas às dimensões em que a maior parte das pessoas entrevistadas sofre maior privação, conforme as necessidades específicas de cada bairro. A maior incidência de privações sofridas pelos entrevistados encontra-se nas dimensões relacionadas à liberdade desfrutada na comunidade, ao acesso à renda, ao trabaIho, a serviços básicos e à educação. Com este resultado, evidenciou-se que a renda monetária não é a única dimensão na qual os indivíduos podem sofrer privação. Existem outras preocupações e outros problemas sofridos pelos indivíduos da amostra que devem ser considerados na elaboração das políticas de combate à pobreza no município.

Ao se levar em conta a decomposição por grupos, tem-se que a atenção às pessoas da Vila Brasília deve ser distinta em relação à atenção dada aos demais grupos, devido à maior privação que elas sofrem. Da mesma forma, ao desagregar por faixa etária, percebe-se que diferentes privações afetam os diversos grupos, sendo que o conhecimento mais aprofundado da natureza das privações pode auxiliar o planejamento público na formulação de ações focalizadas. Este estudo corrobora com a Abordagem das Capacitações ao mostrar que as maiores privações que afetam a população de Silveira Martins não estão relacionadas com a restrição monetária. Mesmo que essa seja importante, também há outros aspectos que devem ser levados em consideração para a mensuração da pobreza.

Além da multidimensionalidade, da consideração de duas linhas de corte, da possibilidade de decomposição por grupos e de segmentação por dimensões e indicadores, a medida de pobreza proposta pelo Método AF representa um avanço em relação às medidas de pobreza anteriores, no que se refere à sua contribuição no âmbito das políticas públicas. É necessária a expansão das capacitações das pessoas por meio de uma maior cobertura de acesso à educação, à saúde, ao saneamento básico, entre outros. Um alargamento nas capacitações encadeia um aumento indireto e direto na liberdade substantiva que as pessoas têm e na diminuição das suas privações. Compreender como a pobreza afeta as pessoas permite um planejamento mais adequado para elaboração e implementação de políticas públicas voltadas à redução da pobreza, uma vez que estarão focalizadas diretamente nas privações sofridas pelas pessoas. 


\section{REFERÊNCIAS}

ATLAS DO DESENVOLVIMENTO HUMANO, 2013. Disponível em: <http://www.atlasbrasil.org. br/2013/>. Acesso em: 19 nov. 2014.

ALKIRE, S. Dimensions of Human Development. World Development. Elsevier Science Ltd, v. 30, n. 2, p. 180-205, 2002.

Why the Capability Approach? Journal the Human Development and Capabilities. United Kingdom, v. 6, n. 1, p. 115-134, 2005.

\section{Choosing dimensions: the capability approach and multidimensional}

poverty. Germany: Munich University Library, 2008. (Munich Personal RePEc Archive Paper, 886). Disponível em: <http://mpra.ub.unimuenchen.de/8862/1/MPRA_paper_8862.pdf>. Acesso em: 15 jan. 2012.

ALKIRE, S. et al. The Alkire-Foster Counting Methodology. In: Multidimensional Poverty Measurement and Analysis. 1st. ed. Oxfort: Oxford University Press, 2015. p. 1-51. v. 1. Disponível em: <https://multidimensionalpoverty.org/contents/>. Acesso em: 16 abr. 2017.

ALKIRE, S.; FOSTER, J. Counting and multidimensional poverty. Oxford: University of Oxford, 2007. (OPHI Working Paper Series, 7).

. Understandings and Misunderstandings of Multidimensional Poverty Measurement. Oxford: University of Oxford, 2011. (OPHI Working Paper Series, 43).

ALKIRE, S.; SANTOS, E. Acute Multidimensional Poverty: A New Index for Developing Countries. Oxford: University of Oxford, 2010. (OPHI Working Paper, 38).

Measuring Acute Poverty in the Developing World: Robustness and Scope of the Multidimensional Poverty Index. Oxford: University of Oxford, 2013. (OPHI Working Paper Series, 59).

ANAND, S; SEN, A. Concepts of Human Development and Poverty: A Multidimensional Perspective. Poverty and Human Development: Human Development Papers. New York: United Nations Development Programme, 1997, p. 1-20.

BARROS, R. P.; CARVALHO, M.; FRANCO, S. Pobreza Multidimensional no Brasil. Rio de Janeiro: IPEA, 2006. (Textos para discussão, 1227).

GALLO, C. R.; ROCHE, J. M. Análisis de la pobreza em Venezuela por Entidades Federales entre 2001 - 2010. Caracas: Banco Central de Venezuela, 2012. (Documentos de Trabajo, 131).

MARIN, S. R. et al. Pobreza Multidimensional em Silveira Martins-RS: Identificação de Dimensões de Vida Valoradas com a Aplicação do Método Alkire-Foster (AF). Gestão Pública e Cidadania. São Paulo, v. 18, n. 62, p. 60-77, 2013.

MARIN, S. R.; OTTONELLI, J. Medida multidimensional de pobreza: um exercício em Palmeira das Missões - RS. Revista Redes. Santa Cruz do Sul, v. 13, n. 3, p. 241-265, 2008. 
MICROSOFT. Microsoft Office Excel 14. [S.I]: Microsoft Corporation, 2010. 1 CD-ROM.

NARAYAN, D. Voices of the poor: Can anyone hear us? Washington, D.C.: The World Bank, Oxford University Press, 2000.

OBJETIVOS DO DESENVOLVIMENTO DO BRASIL (OMD). Agenda de Compromissos 2013-2016. Disponível em: <http://www.objetivosdomilenio.org.br>. Acesso em: 20 mai. 2015.

PROGRAMA DAS NAÇÕES UNIDAS PARA O DESENVOLVIMENTO (PNUD). Human Development Report 2010: The Real Wealth of Nations - Pathways to Human Development. New York: Oxford University Press, 2010.

ROBEYNS, I. An unworkable idea or a promising alternative? Sen's capability approach reexamined. Center for Economic Studies, 2000. (Discussions Paper Series, 00.30)

SANTOS, L. M. dos. Pobreza como privação de liberdade: um estudo de caso na favela do Vidigal no Rio de Janeiro. 2007. 190 f. Dissertação (Mestrado em Economia) — Programa de PósGraduação em Economia, Universidade Federal Fluminense, Rio de Janeiro, 2007.

SEN, A. Poverty: An Ordinal Approach to Measurement. Econometrica. New Haven, v. 44, n. 2, p. 219-231, mar. 1976.

Equality of what? The Tanner Lecture on Human Values. Cambridge: Cambridge University Press, 1979.

. Well-Being, agency and freedom: The Dewey Lectures 1984. The Journal of Philosophy. New York, v. 82, n. 4, p. 169-221, 1985.

. On Ethics and Economics. New York: Basil Blackwell, 1987. . Inequality reexamined. New York: Harvard University Press, 1992.

. Development as Freedom. New York: Anchor Books, 1999a.

Pobreza e fomes: um ensaio sobre direitos e privações. Lisboa: Terramar, 1999b.

. Capabilities, lists, and public reason: Continuing the conversation. Feminist Economics.

Houston, v. 10, n. 3, p. 77-80, 2004. 